\title{
Fatal injury by air gun: a case report
}

\author{
Boris Dumenčić ${ }^{1,2^{*}}$, Jasmina Rajc ${ }^{1,2}$, Deni Pavoković ${ }^{\text {and Tena Damjanović }}{ }^{1,2}$
}

\begin{abstract}
Background: The popularity of air weapons is increasing. They are often viewed as toys, rather than potentially lethal weapons. Regulations on purchase and ownership of air weapons differ from country to country. The majority of fatal and non-fatal air gun accidents involve children less than 16 years of age.

Case presentation: In this report, we present a fatal case resulting from an accident involving an air gun. An accident happened between two brothers aged 9 and 7 and was initially considered to be a traumatic wound inflicted by falling on a scooter handle. Upon the arrival of an experienced police inspector, the cause of child's death was called into question and it was discovered that unlicensed, loaded air gun was left unattended in a backyard shed. It was later established that the cause of death was a fatal gunshot wound to the chest and a pointed lead pellet was found in the boy's liver.
\end{abstract}

Conclusions: The public and governments should be advised that air guns can be dangerous weapons which may cause serious injuries and even death. We believe that air guns should be regulated by the same laws that apply to firearms.

Keywords: Accidents, Death, Weapons, Wounds and injuries, Wounds, Gunshot

\section{Background}

The popularity of air weapons is increasing. They are often viewed more as harmless toys than what they really arepotentially lethal weapons (Aslan et al. 2006). Air weapons propel the projectile (lead pellet or ball bearing) through a barrel by means of compressed air or gas. In some countries, purchase and ownership of air weapons are not subject to any kind of regulations, while in other countries, law regulations vary depending on the energy and velocity of the projectile when it exits the barrel (muzzle energy and velocity). The majority of fatal and non-fatal air weapon injuries occur in children and adolescents (Ceylan et al. 2002).

According to the data from the Ministry of the Interior of the Republic of Croatia, there were 229 acts of criminal offenses by air weapons in the period from year 1998 to year 2018 in the Republic of Croatia. There was a statistically significant increase in the frequency of criminal offenses by air weapons during that period (Mantel-Haenszel Test of Linear Association, $P<0.001$ ) (Fig. 1), especially the offenses of property damage and killing and torture of animals (Mantel-Haenszel Test of

\footnotetext{
* Correspondence: bdumencic29@gmail.com

${ }^{1}$ Faculty of Medicine Osijek, University of Osijek, J. Huttlera 4, HR-31000 Osijek, Croatia

${ }^{2}$ Clinical Department of Pathology and Forensic Medicine, Osijek University Hospital, J. Huttlera 4, HR-31000 Osijek, Croatia
}

Linear Association, $P=0.01$ and $P<0.001$, respectively). The significant increase in air weapon offenses can be explained by the law from 2012 that tightened the consequences of illegal fire weapon possession and use. Great number of Croats still had firearms that were left in their possession after the Croatian War of Independence. Croatian citizens that still had unlicensed and illegal fire weapons from the wartime could have handed them over in police stations until 2012 without legal sanctions. In most cases, people who still wanted to own some kind of weapon decided to get air weapons because of looser legislations around them. Greater ownership of air weapons leads to more criminal offenses by air weapons. In those 69 cases, the result was bodily injury, while only one air weapon-related offense $(0.44 \%)$ resulted in death. We present that case in this report. Although this is not a unique case, it is well documented and illustrated which makes it beneficial for international readership.

\section{Case report}

Two brothers (J. V. and E. V.) aged 9 and 7 were visiting their grandparents. The two of them were riding a children's scooter (Fig. 2a). Nothing was out of the ordinary until E. V. suddenly ran into the house frightened and said that J. V. fell off the scooter and is crying and 


\section{Frequency of cases through the years}

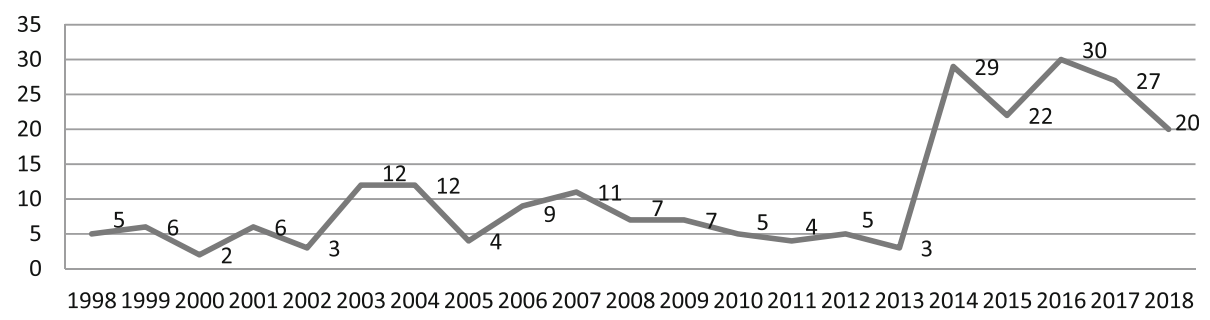

Fig. 1 Number of criminal offenses by air weapons over the examined time period (1998-2018) in the Republic of Croatia

cannot get up. J. V.'s health condition deteriorated rapidly, and his grandmother called emergency medical service in panic. Upon their arrival, J. V. showed no life signs and death was confirmed. The coroner registered a wound on the left lateral side of the chest and assumed that the wound was a result of falling onto the scooter handlebar (Fig. 2b). The coroner suggested that the fractured rib injured the thoracic organs, and the crime

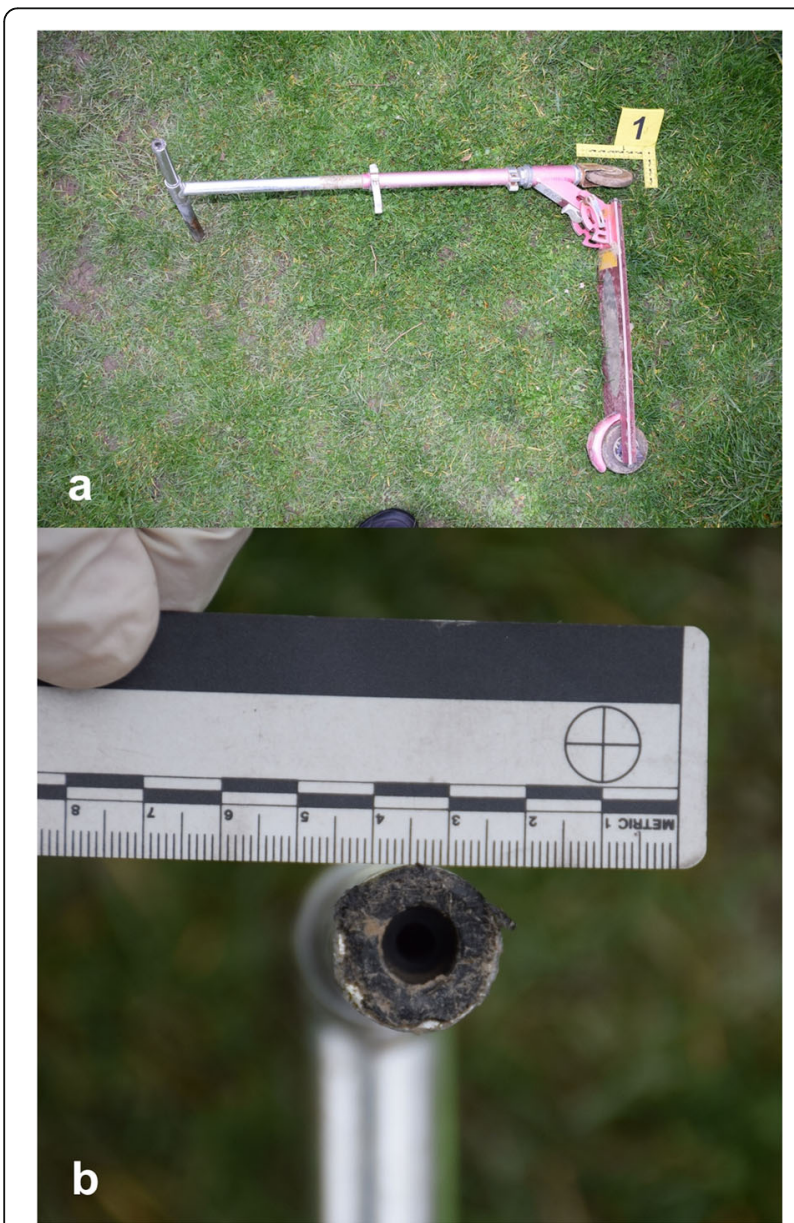

Fig. 2 Display of the children's scooter during the crime scene investigation (a) and of the scooter handlebar (initially suspected cause of injury) (b) scene investigation by the police was started in that direction. In Croatia, the coroner is a physician and, exceptionally, another qualified health care provider who is specially trained to examine the body of the deceased person and to determine the time and cause of death. In this case, the coroner was a young, unexperienced nurse. The coroner determined that the death was accidental, and in that case, autopsy was not mandatory. Upon the arrival of an experienced police inspector, the cause of J. V.'s death was called into question. The inspector photographed the wound using his mobile phone and sent the photographs to a forensic pathologist. After examining the photographs, the forensic pathologist concluded that the wound was most likely a gunshot wound. Such conclusion by the pathologist turned the police investigation in the right direction-to search for the weapon. Only after the phone correspondence with the forensic pathologist was shown to the boy's grandparents did the grandfather admit that he had left a loaded air gun in his backyard shed, a gun that he used for pest control. At the very beginning of the police investigation, the grandfather did not even consider that the air gun could be the source of this fatal event, and he put it away in the house because of the crowd that started gathering in their backyard and because of the arrival of police, since he had not registered the air gun at the police department. During the crime scene investigation, E. V. stated that, while J. V. was riding a scooter, he approached the table where the gun had been left. He said that he only slightly touched the gun without raising it towards J. V. In that moment, he saw his brother falling off the scooter and ran to his grandparents for help.

Autopsy revealed an entrance gunshot wound on the left lateral side of chest, below the 5 th rib, $4 \mathrm{~mm}$ in diameter (Figs. 3a, b and 4a). The wound path ran through the left lung (Fig. 4b), heart (Fig. 4c), and diaphragm, and a pointed lead pellet (caliber $4.5 \mathrm{~mm}$ ) was found deep in the liver (Figs. $4 \mathrm{~d}$ and $5 \mathrm{a}, \mathrm{b}$ ).

A legal proceeding was started against the boy's grandfather for the offense of "Endangerment to Life and Property by a Generally Dangerous Act or Means" (Article 215 of the Croatian Criminal Code). 


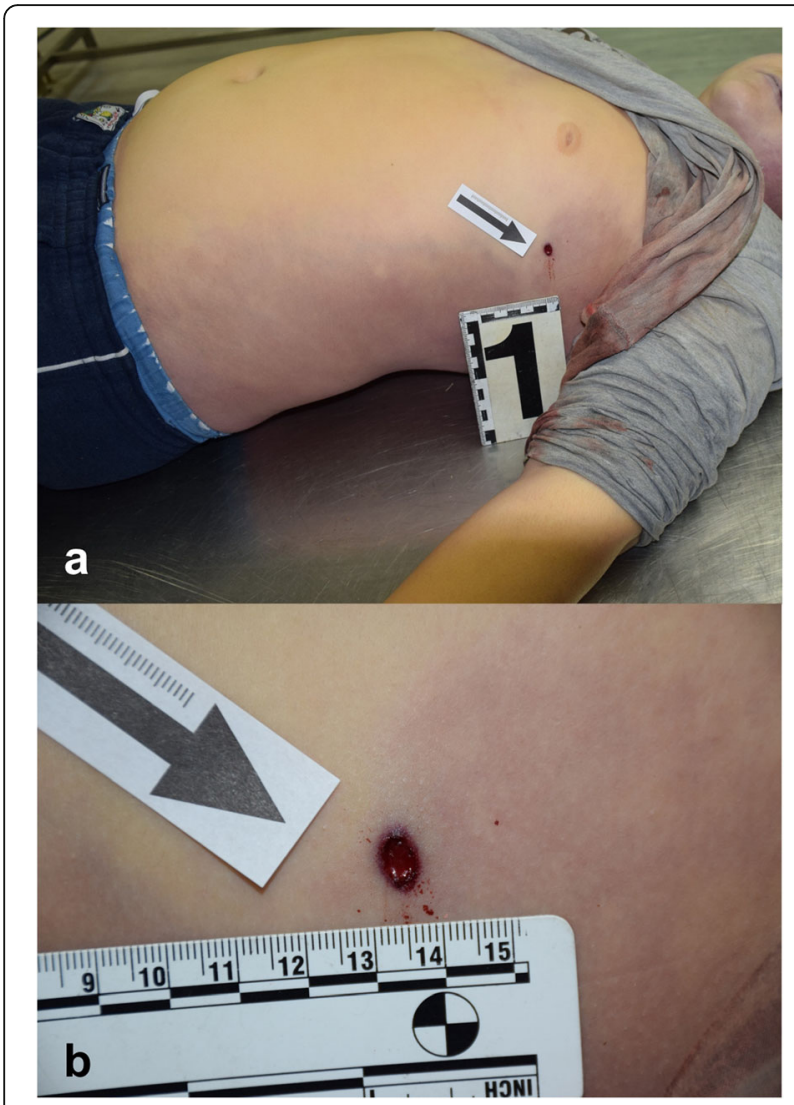

Fig. 3 The wound on the left side of the chest (a) and a close-up of the gunshot wound $(\mathbf{b})$

\section{Discussion}

According to a review by Di Maio, the critical projectile velocity of $70 \mathrm{~m} / \mathrm{s}$ is needed for penetration of the human skin (Di Maio et al. 1982). However, the projectile velocity of modern air weapons is often greater than that and muzzle velocity of many modern air rifles can be similar to that of a conventional hand gun (Naude and Bongard 1996; Robson and Kumar 1985).

Air weapons with muzzle energy of up to $10.5 \mathrm{~J}$ or pellet velocity of up to $200 \mathrm{~m} / \mathrm{s}$ or caliber of up to $4.5 \mathrm{~mm}$ are considered low-power air weapons in Croatia, and such weapons are available for purchase to anyone 18 years of age and above, without license or registration in the police department. The air gun in our case report was Hatsan M 125 , caliber $.177(4.5 \mathrm{~mm})$, pellet muzzle velocity of 380 $\mathrm{m} / \mathrm{s}$ (Fig. 5). According to Croatian law, such rifle can be purchased without license, but after the purchase, it must be registered at the police department. Fatal accidents from air weapons are rare, and minor or major bodily injuries, especially eye injuries, occur more often (Centers for Disease Control and Prevention 1995; Harris et al. 1983). In the UK, approximately one fatal accident from air weapons occurs each year, while in a 5-year study in the USA, a total of 33 fatal cases resulting from the use of

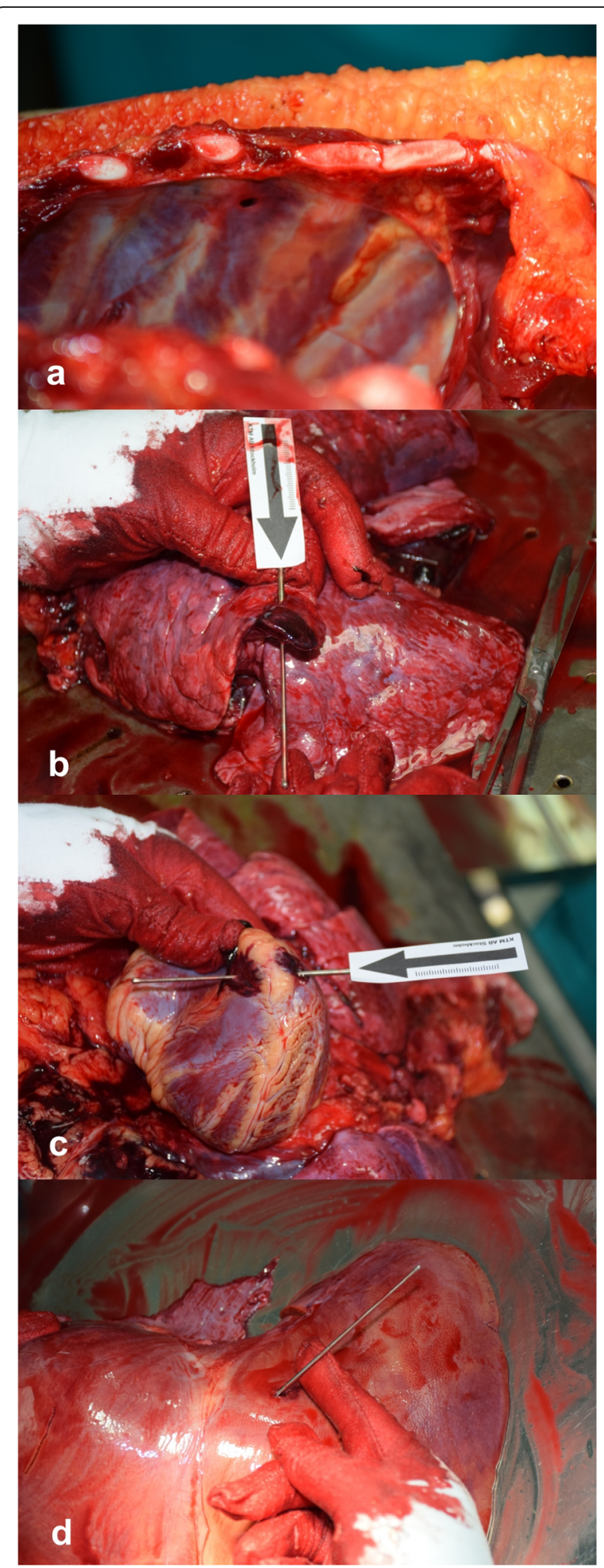

Fig. 4 The wound path running below the 5th rib (a), through the lower left lung (b), through the apex of the heart (c), and entering the left lobe of the liver (d) 


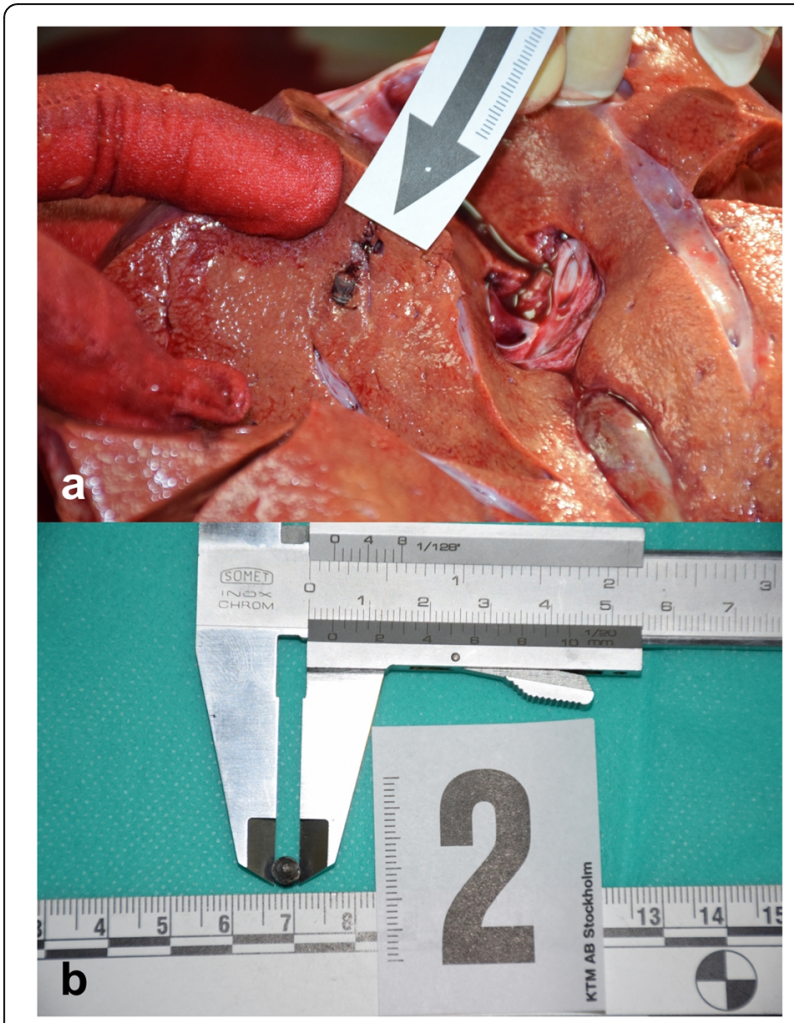

Fig. 5 The 4.5-mm pellet found in the right lobe of the liver (a) and removed during the autopsy (b)

air weapons were recorded (Milroy et al. 1998). In most cases, an accidental shooting by a friend, relative, or a selfinjury is involved, usually in the absence of adult supervision. Children are the most frequent victims of air gun injuries or fatalities, and the assailant is also most often a child (Harris et al. 1983). In all fatal or non-fatal cases, boys are far more often involved than girls. The victims and assailants are most often aged 10 to 14 (Christoffel et al. 1984; McNeill and Annest 1995).

\section{Conclusion}

The public, especially families, as well as governments and legislatures should be advised that air guns are not toys, but dangerous weapons which may cause serious injuries and even death. Furthermore, this case report advocates for more rigorous regulations regarding air guns and raising of safety standards. We believe that air guns should be regulated by the same laws that apply to firearms.

\section{Acknowledgements}

The authors wish to thank Goran Žulj for providing technical details and statistical data.

\section{Authors' contributions}

$\mathrm{BD}$ conceived the presented idea, developed the theory and performed the computations, conducted and analyzed data acquisition process, and discussed results with all authors. JR searched literature, analyzed and interpreted data, and took the lead in writing the manuscript. DP conducted data acquisition process, designed data acquisition, and statistical analysis. TD searched literature, analyzed and interpreted data, and shaped the final manuscript for submission. All authors have approved the submitted version of our case report.

\section{Funding}

This research did not receive any specific grant from funding agencies in the public, commercial, or not-for-profit sectors.

\section{Availability of data and materials}

All data generated or analyzed during this study are included in this published article (and its supplementary information files).

\section{Ethics approval and consent to participate}

This investigation was approved by the Ethical Committee, Faculty of Medicine Osijek, University of Osijek, J. Huttlera 4, 31000 Osijek, Croatia.

\section{Consent for publication}

Not applicable.

\section{Competing interests}

The authors declare that they have no competing interests.

Received: 6 September 2019 Accepted: 31 January 2020

Published online: 10 February 2020

\section{References}

Aslan S, Uzkeser M, Katirci Y, Cakir Z, Bilir O, Bilge F et al (2006) Air guns: toys or weapons? Am J Forensic Med Pathol 27(3):260-262. https://doi.org/10.1097/ 01.paf.0000220919.45493.af

Centers for Disease Control and Prevention (1995) BB and pellet gun-related injuries--United States. June 1992-May 1994. MMWR Morb Mortal Wkly Rep 44(49):909-913

Ceylan H, Mc Gowan A, Stringer MD (2002) Air weapon injuries: a serious and persistent problem. Arch Dis Child 86(4):234-235. https://doi.org/10.1136/adc.86.4.234

Christoffel KK, Tanz R, Sagerman S, Hahn Y (1984) Childhood injuries caused by nonpowder firearms. Am J Dis Child 138:557-561

Di Maio VJM, Copeland AR, Besant-Matthews PE, Flectcher LA, Jones A (1982) Minimal velocities necessary for perforation of skin by air gun pellets and bullets. J Forensic Sci 27(4):894-898

Harris W, Luterman A, Curreri PW (1983) BB and pellet guns-toys or deadly weapons? J Trauma 23:566-569

McNeill AM, Annest JL (1995) The ongoing hazard of BB and pellet gun-related injuries in the United States. Ann Emerg Med 26:187-194

Milroy CM, Clark JC, Carter N, Rutty G, Rooney N (1998) Air weapon fatalities. J Clin Pathol 51:525-529

Naude GP, Bongard FS (1996) From deadly weapon to toy and back again: the danger of air rifles. J Trauma 41:1039-1043

Robson WJ, Kumar K (1985) Air weapon injuries in children: a case for education. Arch Emerg Med 2:17-24

\section{Publisher's Note}

Springer Nature remains neutral with regard to jurisdictional claims in published maps and institutional affiliations. 